\title{
PENSAR El ACELERACIONISMO, ¿CON O CONTRA MARX? EL FRAGMENTO SOBRE LAS MÁQUINAS A DEBATE EN EL S. XXI ${ }^{1}$.
}

\author{
THINKING ACELERACIONISM, WITH OR AGAINST MARX? \\ THE FRAGMENT ON MACHINES UNDER DEBATE IN THE 21 ST CENTURY.
}

\author{
LORENA ACOSTA IGLESIAS - NANTU ARROYO GARCÍA \\ lorenaco@ucm.es - nantu.arroyo@uam.es \\ Universidad Complutense de Madrid y Universidad Autónoma de Madrid (España)
}

RECIBIDO: 06/12/2019
ACEPTADO: $23 / 12 / 2019$

Resumen: En el presente artículo presentamos algunas de las tesis principales del aceleracionismo entendido como un enfoque postmaterialista que pretende alcanzar la revolución social hacia la emancipación total en un estado postcapitalista a través de la aceleración de los procesos tecnológicos. A su vez, exploraremos en qué medida son herederos, como se autodenominan, del diagnóstico marxiano que reposa en el famoso "Fragmento sobre las máquinas" de los Grundrisse. En último lugar, analizaremos cómo afectaría el posicionamiento aceleracionista a la propia teoría del valor marxiana como núcleo fundamental de su crítica.

Palabras clave: aceleracionismo - Marx - fragmento de las máquinas - postcapitalismo - TICs

\begin{abstract}
In this article we present some of the main theses of accelerationism understood as a postmaterialist approach that seeks to achieve social revolution towards total emancipation in a postcapitalist state through the acceleration of technological processes. In turn, we explore to what extent they are heirs, as they call themselves, of the Marxian diagnosis that rests on the famous "Fragment on Machines" of the Grundrisse. Finally, we analyze how the accelerationist positioning would affect the theory of Marxian value itself as the fundamental nucleus of its critique.
\end{abstract}

Key words: aceleracionism - Marx - fragment on machines - postcapitalism - ITC

\section{Introducción}

Si bien es cierto que el S. XX fue por antonomasia el siglo en que las revoluciones sólo pudieron concebirse ya como freno de emergencia -

\footnotetext{
1 Antes de comenzar, quisiéramos agradecer al profesor César Rendueles su amabilidad y disponibilidad al ofrecernos su ayuda y apoyo en el desarrollo de este artículo. Asimismo, queremos destacar que este artículo es el desarrollo de una comunicación con la que participamos en el Congreso Internacional Pensar con Marx hoy, que tuvo lugar en la Facultad de Sociología y Ciencias Políticas de la UCM desde del 2 al 6 de octubre de 2018 y que fue organizado por la FIM (Fundación de Investigaciones Marxistas). A cuyo director, Eddy Sánchez, agradecemos también su apoyo en el desarrollo de este artículo.
} 
emulando las famosas palabras de Walter Benjamin-, los aceleracionistas del S. XXI, formados en la Universidad de Warwick ${ }^{2}$, se empeñan en hacer honor a su nombre y apostar por concebir la revolución social hacia la emancipación total como aceleración de los procesos tecnológicos hacia el postcapitalismo. Qué sea esto del postcapitalismo (como propuesta alternativa al capitalismo como orden social y forma de vida), precisamente en la era post, es algo que quisiéramos dilucidar en las primeras páginas de este escrito.

¿Qué es el aceleracionismo ${ }^{3}$ En sus propias palabras, podríamos decir que «el término ha sido adoptado por un "grupo convergente" de nuevas propuestas teóricas que pretenden conceptualizar el futuro fuera de las críticas tradicionales y regresivas, y de las "soluciones" desacelerativas o restaurativas»" ${ }^{4}$. Frente al fin de la historia y la inexistencia de alternativas proclamadas por el neoliberalismo, el aceleracionismo se reivindica como una "estrategia política" orientada hacia el futuro. Los autodenominados "aceleracionistas" se separan de lo que consideran como izquierda tradicional, ya que, a su juicio, ésta sería incapaz de pensar el futuro de una manera distinta que como apocalipsis, incapaz, por tanto, de ofrecer una alternativa si no es bajo la forma de historias contrafactuales e intervenciones locales, movimientos decrecionistas o "slow" que siguen el razonamiento: $« \mathrm{Si}$ modernidad $=$ progreso $=$ capitalismo $=$ aceleración, entonces la única resistencia posible supone la desaceleración» ${ }^{5}$.

\footnotetext{
${ }^{2}$ En 1995 un grupo de estudiantes de la Universidad de Warwick funda la Unidad de Investigación de la Cultura Cibernética (CCRU, por sus siglas en inglés), en torno al trabajo que realizaban Sadie Plant y Nick Land dentro del Departamento de Filosofía. Los trabajos del colectivo pueden encontrarse en la revista Abstract Culture [http://www.ccru.net/abcult.htm], y más recientemente en el periódico inglés Collapse/Urbatomic [https://www.urbanomic.com], que publica en 2015 un recopilatorio de los escritos del grupo desde que Nick Land tomara la dirección en 1997 hasta 2003. La influencia de Land fue fundamental para el grupo en sus principios; sin embargo, es de vital importancia distinguir entre las distintas derivas del movimiento: el propio Land distingue entre "el aceleracionismo" propiamente dicho, del cual él mismo sería el verdadero artífice, mientras que el aceleracionismo del que fundamentalmente nos ocuparemos aquí, asociado al Manifiesto por una política aceleracionista de Williams y Srnicek, se enmarcaría, más bien, en un pretendido "aceleracionismo de izquierdas".

El grupo se ha caracterizado por utilizar plataformas (anti)académicas para propagar su pensamiento, fundamentalmente en redes sociales, especialmente Twitter (@Xenofeminism @Outsideness@enlightdark@k_punk_unlife ). En la actualidad Nick Land se encuentra en Shanghai autoexiliado, desde donde mantiene operativos los sites Outside in. Involvements with Reality, y Urban Future (2.1).

${ }^{3}$ Para una breve introducción al tema consultar: LAND, N., A quick and dirty introduction to accelerationism, Jacobite, 25 de mayo de 2017, https://jacobitemag.com/2017/05/25/a-quick-anddirty-introduction-to-accelerationism/ Consultado: 15 de septiembre de 2019.

${ }^{4}$ AVANESSIAN A. Y REIS M. (COMPS.) "Introducción" en: Aceleracionismo. Estrategias para una transición hacia el postcapitalismo, Buenos Aires, Caja Negra, 2017, p. 12.

${ }^{5}$ Ibid. p. 11.
} 
¿Cuál es la herramienta para producir esa aceleración que lleve al capitalismo más allá de sí? La tecnología. El aceleracionismo, como "estrategia política" de una nueva izquierda, quiere diferenciarse de buena parte de la izquierda liberal en que, mientras ésta identifica la tecnología con la dominación instrumental y la abandona junto con la economía en manos de sus adversarios a los que combate con constructos teóricos, el aceleracionismo se caracteriza por ver en ella un potencial emancipador sin paragón en el camino hacia un futuro postindustrial. Podría decirse, en efecto, que la tecnología forma parte necesariamente del desarrollo capitalista, pero esto no es un problema para el aceleracionismo, ni para el de izquierdas, ni para el de derechas. Común a todas las tendencias aceleracionistas, la tecnología supone la asunción radical de la subsunción real de la vida bajo condiciones capitalistas: para los aceleracionistas no hay afuera del capital, la tecnología es uno de «los elementos de ese sistema [capitalista] que pueden ser eficaces en una transición concreta a otra forma de vida» ${ }^{6}$-no olvidemos el subtítulo de uno de los principales libros que divulgan el mantra aceleracionista: estrategias para una transición hacia el postcapitalismo-.

La tecnología se considera como un producto histórico concreto de raíz capitalista, pero intrínsecamente social y "separable" de su apropiación capitalista. Según el proyecto político de lo que llamaremos "aceleracionismo de izquierdas" la clave está en reinterpretar los fenómenos científicos y económicos-financieros del último siglo en clave postmaterialista, los cuales habrían sido largamente ignorados por la academia como consecuencia del legado del 68 que, atrincherándose en «la construcción de un bastión contra el capitalismo» ${ }^{7}$ habría contribuido a la crisis político-económica e intelectual de la universidad $^{8}$.

Crisis, cuyos presupuestos neoliberales asumen como plataforma para lanzar sus propuestas de cuño aceleracionista. Esto es, toman como premisa teórica el desarrollo productivo y tecnológico que ha traído consigo el neoliberalismo y aprovechan sus crisis como oportunidad para desarrollar una posición más progresista a partir de posiciones políticas que consideran más radicales, como el postoperaísmo, el tecnofeminismo o el pensamiento rizomático y nomádico de Deleuze y Guattari, todas ellas propuestas nacidas y desarrolladas fuera de la academia ${ }^{9}$.

\footnotetext{
${ }^{6}$ Ibid. p. 12.

7 AVANESSIAN, A., "Epílogo: Academia en aceleración", en AVANESSIAN A. Y REIS M. (COMPS.), Op. Cit., p. 268.

${ }^{8}$ Cfr. Ibid., pp. 267-287.

${ }^{9} \mathrm{El}$ aceleracionismo como movimiento generacional ha estado vinculado a la academia en un periodo de máximo auge y desarrollo de las tecnologías de la información, las cuales no hacen sino reflejar el
} 
El aceleracionismo en su conjunto se conecta explícita y repetidamente con los análisis de Deleuze y Guattari. Por un lado, con su concepción inmanente de las máquinas sociales y técnicas $\mathrm{y}$, por otro, con su opción por "acelerar el proceso" de desterritorialización, ambos principios rectores del "aceleracionismo" están extraídos de El Anti-Edipo. Siendo así, nos vemos obligadas a traer a colación una de las citas más reiterativas que uno se encuentra en prácticamente la totalidad del corpus textual aceleracionista:

«Pero, ¿qué vía revolucionaria, hay alguna? ¿Retirarse del mercado mundial como aconseja Samir Amin a los países del tercer mundo, en una curiosa renovación de la "solución económica" fascista? ¿O bien ir en sentido contrario? Es decir, ir aún más lejos en el movimiento del mercado, de la descodificación y de la territorialización. Pues tal vez los flujos no están aún bastante desterritorializados, bastante descodificados, desde el punto de vista de una teoría y una práctica de los flujos de alto nivel esquizofrénico. No retirarse del proceso, sino ir más lejos, "acelerar el proceso", como decía Nietzsche: en verdad, en esta materia todavía no hemos visto nada» ${ }^{10}$.

La pregunta cardinal que guía la motivación aceleracionista en su dimensión de proyecto político es precisamente la insistencia en la posibilidad fáctica de la revolución hoy. Pareciera una pregunta un tanto anacrónica ${ }^{11}$ teniendo en cuenta que el Siglo de las revoluciones, el XIX, nos queda ya lejano. A partir de entonces, todas las vías de transformación social se han centrado en formas de resistencia ante la acelerada expansión del neoliberalismo y el capitalismo financiero. Esto supone precisamente una de las grandes denuncias del aceleracionismo contra lo que denominan como "política folk"12, cuyas prácticas

tipo de sociabilidad al que induce la tecnología digital. Tal y como señala César Rendueles su tipo de sociabilidad «no sería tanto el de la reticularidad como la de un vínculo social refractario a la institucionalidad» RENDUELES, C., "Tecnociencia y posthumanismos: del general intellect al ciberfetichismo" en: ACOSTA, L., y LÓPEZ, P., (Eds.), La técnica moderna y las "superaciones del hombre", Guillermo Escolar Editor, 2019, p. 197. De ahí que el tipo de plataformas de lanzamiento para las teorías aceleracionistas sean editoriales, periódicos, revistas, páginas web, blogs, y fundamentalmente redes sociales como Twitter, el espacio al que se reduciría la democracia hoy, según palabras de Jodi Dean, y que los aceleracionistas utilizarían como soporte transformador antropológico que sirve como punto de partida para construir una democracia supuestamente radical.

${ }^{10}$ DELEUZE, G., Y GUATTARI, F., El Anti-Edipo, Barcelona, Paidós, 1985, p. 246.

${ }^{11}$ BYUNG-CHUL HAN, ¿Por qué hoy no es posible la revolución?, El país, 3 de octubre de 2014: https://elpais.com/elpais/2014/09/22/opinion/1411396771_691913.html. Consultado: 13 septiembre 2019.

${ }^{12}$ «¿Qué es la política folk? La política folk identifica una constelación de ideas e intuiciones dentro de la izquierda contemporánea que moldea las formas de organizarse, actuar y pensar la política dentro del sentido común. Es un conjunto de supuestos estratégicos que amenaza con debilitar a la 
políticas basadas en la acción directa y una estructura horizontalista tendrían como límite interno el establecimiento de «pequeños espacios temporales de relaciones sociales no-capitalistas ${ }^{13}$, rehuyendo, sin embargo, los problemas reales que tienen un alcance global, y que sólo podrían enfrentarse adecuadamente con una revolución de las mismas dimensiones, o por decirlo en palabras de Ellen Willis, muy citada por Mark Fischer: «una revolución social y psíquica de magnitud casi inconcebible» ${ }^{14}$.

Dicha revolución global sería, según los aceleracionistas, hace ya mucho tiempo posible gracias al nivel de desarrollo de la tecnología digital y la expansión reticular de las interconexiones mundiales que supondría Internet. Sin embargo, este fenómeno no dejaría de circunscribirse localmente de manera diferenciada, conviviendo así con la subsunción real del capital que, en el fondo, es simplemente síntoma de las estructuras del capital globalizado cristalizado ideológicamente en una idea banal de cosmopolitismo ${ }^{15}$.

\section{Puntos cardinales del aceleracionismo: actores y temáticas centrales.}

Expondremos ahora, en primer lugar, las tesis fundamentales en las que se apoya el aceleracionismo. Éstas las encontramos bien sintetizadas en el vademécum aceleracionista por excelencia: el Manifiesto por una Política aceleracionista ${ }^{16}$ de Alex Williams y Nick Srnicerk.

Williams y Srnicerk, encauzando la gran corriente aceleracionista, ven obsoleto el intento desesperado de la mayoría de los partidos políticos de la izquierda de retornar a un Estado de bienestar por la vía keynesiana. No hay

\footnotetext{
izquierda, volviéndola incapaz de crecer, generar cambios duraderos o expandirse más allá de los intereses particulares. Los movimientos de izquierda influidos por la política folk no sólo tienen pocas probabilidades de ser exitosos: a decir verdad, son incapaces de transformar el capitalismo. El término mismo se deriva de los sentidos de folk. En primer lugar, evoca algunas críticas a la psicología folk según las cuales nuestras concepciones intuitivas del mundo están construidas históricamente y a menudo equivocadas. En segundo lugar, se refiere a folk como la sede de la pequeña escala, lo auténtico, lo tradicional y lo natural. La idea de política folk comprende estas dos dimensiones.» SRNICEK, N., Y WILLIAMS, A., Inventar el futuro. Poscapitalismo y un mundo sin trabajo, Barcelona, Malpaso, 2015, pp. 17 y 18.

13 WILLIAMS, A. Y SRNICEK N., "Manifiesto por una política aceleracionista", en: AVANESSIAN A. Y REIS M. (COMPS.), Op. cit. p. 39.

14 FISCHER, M., "Una revolución social y psíquica de magnitud casi inconcebible": Los interrumpidos sueños aceleracionistas de la cultura popular, en: AVANESSIAN A. Y REIS M. (COMPS.), Op. cit., pp. 153-165.

${ }^{15}$ Cfr. RENDUELES, C., Op. Cit. p. 193.

${ }^{16}$ A partir de ahora, cuando hagamos referencia a dicho texto será MPA.
} 
ningún pasado idílico al que volver. El futuro ha de ser construido. Para ello, la acción directa y el horizontalismo intransigente, armas habituales de la izquierda del S. XX —retomadas recientemente por los movimientos sociales ${ }^{17}$ - resultan impotentes, limitándose internamente a sí mismas y conformándose con intervenciones locales, renunciando con ello a la posibilidad de una "verdadera" revolución social para transformar el capitalismo. Los autores del MPA acusan a los movimientos horizontalistas de quedar «atrapados en los límites de la política folk» ${ }^{18}$ debido a los medios utilizados para vencer la dominación. Sin embargo, dicha acusación podría volverse fácilmente contra los propios aceleracionistas, ya que, al necesitar de un alto grado de desarrollo de las TIC inscritas en la dinámica capitalista, quedan atrapados dentro de los límites internos del capitalismo y por ello necesitan del prefijo post. No se trata, efectivamente, de una posición meramente anticapitalista, sino que su programa político pretende reabsorber y aprovechar las fuerzas productivas latentes de la tecnología, cuya finalidad el capitalismo se empeña en reducir a la mera y absoluta valorización: «Una política aceleracionista busca preservar las conquistas del capitalismo tardío al tiempo que va más allá de lo que su sistema de valores, sus estructuras de control y sus patologías de masa permiten» ${ }^{19}$.

También se ha llegado a un punto de no retorno respecto al grado de modernización como para desear volver al fordismo y su forma de organización industrial del trabajo: «a pesar de la nostalgia que muchos pueden sentir, el regreso a este régimen es tanto indeseable como imposible» ${ }^{20}$. Es más, al querer liberar las fuerzas productivas latentes, necesitan de la base material del neoliberalismo como plataforma para redirigir las herramientas tecnológicas

\footnotetext{
17 «Viendo hacia atrás, tenemos el colapso de las organizaciones tradicionales de la izquierda y el ascenso simultáneo de una nueva alternativa de izquierda basada en críticas a la burocracia, la verticalidad, la exclusión y la institucionalización, combinadas con la incorporación de algunos de los nuevos deseos en el sistema del neoliberalismo. Fue con este telón de fondo como las instituciones de la política folk se fueron sedimentando como un nuevo sentido común y llegaron a ser expresadas en los movimientos alterglobalizadores. Estos movimientos surgieron en dos etapas. La primera, que apareció a partir de mediados de los años noventa hasta principios de la primera década del siglo XXI, consistió en grupos como los zapatistas, anticapitalistas, alterglobalizadores y los participantes en el Foro Social Mundial y las protestas globales contra la guerra. Una segunda etapa comenzó inmediatamente después de la crisis financiera de 2007-2009 y comprendió a varios grupos unidos por sus formas de organización y posturas ideológicas similares, incluidos el movimiento Occupy, el $15 \mathrm{M}$ de España y varios movimientos estudiantiles en el ámbito nacional.» SRNICEK, N., Y WILLIAMS, A., Op. Cit., 2015, pp. 35 y 36.

${ }^{18}$ SRNICEK, N., Y WILLIAMS, A., Ibid., p. 42.

19 SRNICEK, N., Y WILLIAMS, A., "Manifiesto por una política aceleracionista", en: AVANESSIAN A. Y REIS M. (COMPS.), Op. cit., p. 39.

${ }^{20}$ Ibid., p. 40.
} 
innovadoras hacia objetivos comunes ${ }^{21}$, ya que toda la infraestructura que se necesita para ello ha sido brindada gracias a su alto grado de desarrollo. Sin embargo, al estar postrada únicamente a los fines capitalistas de valorización «aún no sabemos lo que un cuerpo tecno-social moderno puede hacer» ${ }^{22}$.

Por otro lado, esto no significa necesariamente que se enmarquen en una posición tecno-utopista que crea ingenuamente que "sólo la tecnología puede salvarnos" ya que insisten en que «la democracia no puede ser definida simplemente por sus medios ${ }^{23}$, sino que la tecnología se presenta como condición necesaria pero no suficiente: la estrategia socio-política en la cual se encarnarían como proyecto político resulta clave para superar los conflicto sociales generados por el capital.

Estas plataformas establecen los parámetros básicos de lo posible tanto en el ámbito conductual como en el ideológico. En este sentido, encarnan el material transcendental de la sociedad: son lo que hace posibles determinados grupos de acciones, relaciones y poderes. Que mucho de la actual plataforma global esté orientado a favor de las relaciones sociales capitalistas, no es una condición inevitable $e^{24}$.

De hecho, Williams y Srnicek ponen un ejemplo fáctico como "paradigma de esta actitud experimental": el proyecto chileno Cybersynn". En este caso, se

\footnotetext{
${ }^{21}$ Cfr. Ibid., pp. 40 y 41.

${ }^{22}$ Ibid., p. 41.

${ }^{23}$ Ibid., p. 44.

${ }^{24}$ Ibid., pp. 42 y 43 .

${ }^{25}$ «En 1971, durante el gobierno del presidente Salvador Allende, se comienza a desarrollar en Chile un innovador sistema cibernético de gestión y transferencia de información. El proyecto se llamó CYBERSYN, sinergia cibernética, o SYNCO, sistema de información y control. En las empresas del área de la propiedad social del Estado de Chile se implementaría un sistema de transferencia de información económica a "casi" tiempo real con el gobierno. Después de nacionalizar y anexar diversas empresas de propiedad social al estado, el sistema económico del Gobierno de Allende se enfrentó a la necesidad de coordinar toda la información de las empresas estatales y las recientemente nacionalizadas. Para lograrlo, se necesitó crear un sistema de transferencia de información dinámico y flexible. En 1970, Fernando Flores fue nombrado Director General Técnico de CORFO (Corporación para el Fomento de la Producción de Chile). Comenzó a ser el responsable de la gestión y coordinación entre las empresas nacionalizadas y el estado. Conocía las teorías y las soluciones propuestas por el británico Stafford Beer desde que era estudiante de ingeniería y posteriormente por su relación profesional con la empresa de consultoría de Stafford Beer SIGMA. Junto a Raúl Espejo, quien también trabajaba en CORFO, escribió una carta a Stafford Beer con el propósito de invitarlo a implementar en Chile el VSM (modelo de sistema viable), modelo que describía en su libro The brain of the firm ( $1^{\mathrm{a}}$ edición 1967). Beer aceptó y el proyecto comenzó su desarrollo en 1971. Luego de varios meses de gestación y de avances inimaginables, el proyecto de gobierno cibernético fue aprobado por el Presidente Salvador Allende para ser implementado en el Palacio La Moneda.
} 
observa cómo es posible fusionar las «tecnologías cibernéticas avanzadas con técnicas de modelación económica sofísticas y una plataforma democrática materializada en la infraestructura tecnológica misma ${ }^{26}$. Ejemplo que, aunque los aceleracionistas promueven como estrategia política hacia el postcapitalismo, no deja de ser un caso histórico del socialismo.

De cara a concretar el programa de su proyecto político, Williams y Srnicek se proponen tres objetivos específicos a medio plazo $^{27}$ :

1. En primer lugar, construir una fuerte infraestructura intelectual creando una nueva ideología capaz de acompañar el cambio político radical y con ella, las instituciones y vías materiales para llevarlo a cabo.

2. En segundo lugar, articular «una reforma de los medios de comunicación a gran escala» ${ }^{28}$ de cara a disminuir el control social de los medios tradicionales de comunicación y democratizar realmente los canales comunicativos que ofrece Internet.

3. Y, por último, «reconstituir diversas formas del poder de clase» ${ }^{29}$ de cara a poder integrar las diferentes identidades proletarias que se encarnan en las actuales formas postfordistas de trabajo precario.

Sin embargo, no creen que «la acción directa sea suficiente para alcanzar ninguno de estos objetivos [ya que] las tácticas habituales de marchas con pancartas y de creación de zonas temporalmente autónomas corren el riesgo de convertirse en reconfortantes sustitutos del éxito efectivo» ${ }^{30}$. Por ello, se posicionan contra la izquierda contemporánea —o lo que ellos llaman "política folk"-, ya que creen que se obceca en fetichizar la horizontalidad, la inclusión social y la democracia como proceso y cuya herencia creen que procede de una mala comprensión generalizada del proyecto ilustrado por parte de la izquierda, el cual los aceleracionistas comprenden, curiosamente, como el autodominio colectivo junto con el desarrollo tecnológico que nos ha brindado el neoliberalismo ${ }^{31}$.

Lamentablemente, debido al golpe militar del 11 de Septiembre de 1973, Cybersyn o Synco nunca pudo ser aplicado y fue abortado irrevocablemente, frustrando uno de los proyectos políticos y cibernéticos más avanzados de la época en el mundo.» Fuente electrónica: http://www.cybersyn.cl/castellano/cybersyn/ [Consultado: 15 de septiembre 2019].

${ }_{26}$ SRNICEK, N., Y WILLIAMS, A., "Manifiesto por una política aceleracionista" en: AVANESSIAN A. Y REIS M. (COMPS.), Op. Cit., p. 42.

${ }^{27}$ Cfr. Ibid., p. 44 y 45.

${ }^{28}$ Ibid., p. 45.

${ }^{29}$ Ibid.

${ }^{30}$ Ibid., p. 43.

${ }^{31}$ «Necesitamos recuperar el argumento tradicionalmente formulado a propósito del postcapitalismo: el capitalismo no es sólo un sistema injusto y perverso, sino también un sistema que frena el progreso. Nuestro desarrollo tecnológico está siendo paralizado por el capitalismo en la misma 
Si hay algo que comparte Nick Land, gurú del aceleracionismo de derechas, con Williams y Srnicek es precisamente la crítica a cierto revisionismo de izquierdas del proyecto ilustrado — si bien es cierto que Nick Land lo desecha completamente, incluso llegando a llamarlo "miserabilismo transcendental" 32 -; Williams y Srnicek intentan retomarlo contra la izquierda contemporánea con las herramientas tecnológicas del neoliberalismo.

Lo que claramente distancia al aceleracionismo de izquierdas del de derechas - el cual Nick Land enfatiza como "EL aceleracionismo" 33 - es que, si bien Nick Land defiende alegremente que el verdadero sujeto de la aceleración es el capital y que éste es indisociable a su vez de las herramientas tecnológicas y el proceso de modernización; Williams y Srnicek se empeñan en distinguir ambas esferas cayendo — podríamos decir- en una autonomía de lo político que mediaría entre ambas acelerando el proceso de cara a la revolución social ${ }^{34}$.

medida en la que fue desencadenado por él. El aceleracionismo es la convicción de que estas capacidades pueden y deben ser liberadas, y elevarse por encima de las limitaciones que impone la sociedad capitalista. Superar nuestras restricciones actuales implica más que una simple lucha por una sociedad global más racional. Creemos que debe incluir también la recuperación de los sueños que fascinaron a muchos desde mediados del siglo XIX hasta los albores de la era neoliberal, sueños del homo sapiens en busca de expansión más allá de los límites del planeta y nuestras formas corporales inmediatas. Estas visiones son consideradas hoy reliquias de una época más inocente. Aun así, ponen de relieve la asombrosa falta de imaginación de nuestro tiempo y ofrecen la promesa de un futuro afectivamente vigorizante e intelectualmente energizante. Después de todo, solo una sociedad postcapitalista posible gracias a una política aceleracionista será capaz de cumplir las promesas que generaron los programas espaciales de mediados del siglo XX e ir más allá de un mundo hecho de pequeñas mejoras técnicas hacia un cambio integral. Hacia una era de autodominio colectivo, y hacia el futuro propiamente alienígena que implica y posibilita. Hacia la culminación del proyecto de autocrítica y autodominio de la Ilustración, más que hacia su eliminación.» Ibid., p. 47.

32 «De aquí el silogismo Miserabilista Transcendental: el tiempo está del lado del capitalismo, el capitalismo es todo lo que me entristece, por tanto el tiempo debe ser malo. Los osos polares se están ahogando, y no hay absolutamente nada que podamos hacer. El capitalismo continúa acelerando, aun cuando ya ha producido novedades más allá de toda imaginación humana previa.» LAND, N., "Crítica del miserabilismo transcendental" en: AVANESSIAN, A., Y MAURO, R., Op. Cit., p. 67.

${ }^{33}$ Land, Nick (@Outsideness) “Testicular semio-fascism is all that's left now. Probably a felling sperm-count compensatory mechanism of some kind". 10:59 - 10 sept. 2018 Tweet.

${ }^{34}$ "Against these new approaches, Nick Land, in 'Teleoplexy', insists that it is the practice of forward-looking capitalization alone that can produce the futural dynamic of acceleration. Against Williams and Srnicek, for whom 'capitalism cannot be identified as the agent of true acceleration', and Negarestani, for whom the space of reasons is the future source from which intelligence assembles itself, Land argues that the complex positive feedback instantiated in market pricing mechanisms is the only possible referent for acceleration». AVANESSIAN, A., Y MACKAY, R., "Introduction" en: VV.AA., \#Acelerate\# The acelerationist reader, United Kingdom, Merve Verlag, 2014, p. 34. 


\begin{abstract}
¿Es la aceleración una condición para el colapso final del poder capitalista? Difícil creerlo: la aceleración es la forma esencial del crecimiento capitalista: el incremento en la productividad implica una intensificación del ritmo de producción y de explotación. La hipótesis aceleracionista pone de relieve las implicaciones contradictorias del proceso de intensificación, enfatizando en particular la inestabilidad que la aceleración produce dentro del sistema capitalista. Contra esta hipótesis, no obstante, mi respuesta a la pregunta de si la aceleración marca el colapso final del poder es muy simple: no, porque el poder del capital no está fundado en la estabilidad ${ }^{35}$
\end{abstract}

Por otro lado, los autores del MPA se instituyen - también - como los únicos y verdaderos aceleracionistas, ya que a pesar de reconocer su estructura de filiación con Nick Land consideran que «el neoliberalismo landiano confunde, sin embargo, velocidad con aceleración ${ }^{36}$. Retomando, por el contrario, la cita anterior de Bifo, también pudiera indicarse que, si el objetivo de Williams y Srnicek es acabar con las estructuras capitalistas por mor de la revolución social acelerando los procesos productivos; dicha aceleración, no hará sino alimentar la propia dinámica capitalista «porque el poder del capital no está fundado en la estabilidad» ${ }^{37}$.

El problema con ese argumento es que mientras Land tiene un sujeto para la aceleración -el capitalismo- y una estética —el jungle y el drum and bass-, al aceleracionismo contemporáneo parece faltarle los dos. Si el momento actual es estático, entonces, ¿de dónde vendría el aceleracionismo ${ }^{38}$.

Al faltarle al aceleracionismo de izquierdas un sujeto para la revolución, se proponen conformar una política prometeica ${ }^{39}$ capaz de fundar la mutación

\footnotetext{
${ }^{35}$ BIFO, F., "El aceleracionismo cuestionado desde el punto de vista del cuerpo" en: AVANESSIAN A. Y REIS M. (COMPS.), Op. Cit., p. 69.

${ }^{36}$ Ibid. p. 37.

${ }^{37}$ Ibid.

${ }^{38}$ NOYS, B., "Baila y muere: obsolescencia y aceleración" en: AVANESSIAN A. Y REIS M. (COMPS.), Op. Cit., p. 193.

${ }^{39}$ "A este respecto, el prometeísmo es simplemente la reivindicación de que no hay razón alguna para asumir un límite predeterminado a lo que podemos alcanzar o a los modos en lo que podemos transformarnos a nosotros mismos y transformar nuestro mundo. [...] Pero, ¿qué hay exactamente de razonable en la aceptación del nacimiento, el sufrimiento y la muerte como hechos dados ineluctables, es decir, como algo dado? Y, ¿a través de qué criterio debemos distinguir entre el sufrimiento evitable y el inevitable?» BRASSIER, R., "El prometeísmo y sus criticos" en: AVANESSIAN, A., Y MAURO, R., (Coomps.), Ibid., pp 203 y 204.
} 
antropológica que sirva de base para el cambio social. Para ellos, ésta sería la manera de recuperar el proyecto ilustrado mediante la incorporación de la tecnología como transformador antropológico, el cual resulta necesario para llegar a trascender las limitaciones humanas, tanto de cara a la gestación de nuevos feminismos ${ }^{40}$, como respecto de la posibilidad de crear vida sintética, ambos con ayuda de la tecnología y traspasando así los límites entre lo viviente y no-viviente desde un enfoque post-humanista ${ }^{41}$.

Por otro lado, si bien es cierto que el sujeto del cambio es un asunto pendiente para el aceleracionismo de izquierdas, no parece tan cierto que no provenga, al menos sociológicamente, de una cierta cultura y estética que se habrían apropiado políticamente: la cultura rave. En palabras de Land, esta intensificación de los elementos acelerativos de la cultura dance resultó en que «la inminente extinción humana se hizo accesible como pista de baile» ${ }^{42}$.

La opción aceleracionista de izquierdas del grupo reunido en torno al CCRU en la Universidad de Warwick es resultado de su herencia cultural. Nacidos entre 1960 y 1970 su "aceleracionismo" se hace cargo de la experiencia sesentayochista, posmoderna y cibernética llevada al medio universitario anglosajón, cuyas experiencias comunitarias no tienen nada que ver con $\mathrm{La}$ Comuna de París — que no dejaba de ser el referente para Mayo del 68-, sino con las macro-fiestas-sintéticas (raves).

Entre los factores clave para el desarrollo de la nueva forma de aceleracionismo que encontramos aquí está la aventura farmaco-social-sensorial-tecnológica colectiva de la cultura rave y la simultánea invasión de los hogares por las tecnologías mediáticas (VCRS, videojuegos, computadoras) y la inversión popular en ciencia ficción ciberpunk distópica, que incluye la trilogía de William Gibson Neuromante y los films Terminator, Predator y Blade Runner (que se convirtieron en "textos" claves para estos autores) ${ }^{43}$.

El teórico aceleracionista de la cultura Mark Fischer encuentra en la música popular «uno de los motores de la aceleración cultural desde fines de los años

\footnotetext{
${ }^{40}$ Cfr. CUBONIKS, L., "Xenofeminismo: una política por la alienación” en: AVANESSIAN, A., Y MAURO, R., (Comps.), Ibid., pp. 117-133.

${ }^{41}$ Cfr. BRASSIER, R., Ibid., pp. 217 y 218.

${ }^{42}$ NICK LAND apud. por NOYS, B., en "Baila y muere: obsolescencia y aceleración" en: AVANESSIAN A. Y REIS M. (COMPS.), Op. Cit., p. 185.

${ }^{43}$ AVANESSIAN A. Y REIS M., Op. cit., p. 26.
} 
cincuenta hasta los $2000 »^{44}$, haciendo coincidir el surgimiento de la estrategia aceleracionista con el despertar de la contracultura de los años sesenta y setenta. En la misma línea, Benjamin Noys cifra históricamente la promesa de aceleración en el futurismo del siglo $\mathrm{XX}^{45}$ y utiliza la música popular y su tendencia a utilizar cada vez ritmos más rápidos como correlato de los distintos momentos de aceleración capitalista — por ejemplo, la cultura "rave" de Gran Bretaña, el techno de Detroit de principios de los años ochenta, y, más recientemente, la música dance-. Éstos funcionarían como bisagras a la hora de desencadenar una "verdadera" estrategia aceleracionista que pueda volverse contra el capitalismo. Por un lado, la aceleración entre los 160 y los 180 bpm del jungle y el drum and bass permitió a Land pensar la posible integración de lo humano con lo maquínico y lo tecnológico; pero esta no deja de ser otra mitología más ${ }^{46}$, ya que el único sujeto posible de esta aceleración inhumana es siempre el capital mismo: las fuerzas de producción capitalista como el único sujeto posible. Por otro lado, el techno de Detroit volvió a aumentar los bpm y eliminó de su música todo residuo humanista: «el techno de Detroit era música conscientemente postfordista y postindustrial» ${ }^{47}$. De hecho, el sello Motown fue fundado por Berry Gordy, un obrero de la industria del automóvil, sobre los principios fordistas como banda sonora para la cadena de montaje.

Los aceleracionistas repiten una y otra vez que el techno es producto de una estética postindustrial, haciendo referencia tanto a la aceleración del tempo como a los medios tecnológicos que se han introducido masivamente en la producción musical. Sin embargo, hay condiciones mucho más evidentes que señalan esta cuestión y que ellos obvian debido a su enfoque postmaterialista: la condición sociológica por la cual el techno pudo volver a ocupar las fábricas, abandonadas en los noventa, lo cual señala claramente el acoplamiento del aceleracionismo a la irrupción del neoliberalismo.

La aceleración que atraviesa el plano estético tiene su fundamento material y empieza a percibirse como un fenómeno socialmente global únicamente cuando la revolución microelectrónica se ha llevado a cabo: uno de los puntos claves que aborda el aceleracionismo es la consideración de los algoritmos como capital fijo $^{48}$ debido al cambio suscitado por el capitalismo financiero.

44 FISCHER, M., ““Una revolución social y psíquica de magnitud casi inconcebible”: los interrumpidos sueños aceleracionistas de la cultura popular" en: AVANESSIAN A. Y REIS M. (COMPS.), Op. cit., p. 156.

${ }^{45}$ Cfr. NOYS, B., "Baila y muere: obsolescencia y aceleración”, Op. cit., p. 181.

${ }^{46}$ THORNTON, S. Club Cultures, Oxford, Polity Press, 1995, apud. NOYS, B., Ibid. p. 186.

${ }^{47}$ NOYS, B., "Baila y muere: obsolescencia y aceleración", Op. cit., p. 188.

${ }_{48}^{4}$ «Con todo desde el punto de vista del capitalismo, los algoritmos son principalmente una forma de "capital fijo", es decir, son simplemente medios de producción. Codifican una cierta cantidad de 
De esta manera, los aceleracionistas trasladarían la consideración marxiana de la maquinaria como capital fijo a la implicación entre capital y tecnología: debido a la productividad exacerbada que se consigue mediante la introducción de algoritmos en el surgimiento del capitalismo financiero y de Internet en el proceso productivo mediante el trabajo postindustrial, el tiempo inmediato de trabajo humano desaparece como algo infinitamente pequeño. Los algoritmos funcionarían como medios de producción con capacidad para producir valor ${ }^{49}$ aun cuando no se identifiquen inmediatamente con su existencia como capital. Por un lado, esto dejaría obsoleta la teoría del valor marxiana y, por otro, les permite tomar la tecnología como herramienta neutral, independiente de su forja por el capital, para revertirla en el cambio político porvenir ${ }^{50}$. Éste se produciría a través de tres niveles de innovación socio-tecnológica: el dinero virtual como «dinero del común» ${ }^{51}$, las redes sociales «para producir procesos masivos de participación y deliberación ${ }^{52}$ y los bio-hipermedia en tanto que producen una relación íntima con el dispositivo «influyendo en el modo en que sentimos, percibimos y entendemos el mundo» ${ }^{53}$.

De hecho, aun cuando los aceleracionistas proponen explorar la habitabilidad del espacio exterior en un intento de refundar la era del Antropoceno fusionando

saber social (extraída de lo que los elaboran matemáticos, programadores, y también las actividades de los usuarios), pero no son valiosos en sí mismos. En la economía contemporánea, son valiosos solo en la medida en que permiten la conversión de tal saber en valor de cambio (monetización) y su (exponencialmente creciente) acumulación (los titánicos cuasimonopolios de la Internet social). En la medida en que constituyen capital fijo, algoritmos como PageRank de Google o EdgeRank de Facebook aparecen "como supuesto frente al cual la fuerza valorizadora de la capacidad laboral individual desaparece como algo infinitamente pequeño", y es por esto que las demandas de retribuciones individuales por el "trabajo gratuito" de los usuarios están mal conceptualizadas.» TERRANOVA, T., "Red Stack attack! Algoritmos, capital y la automatización del común" en: AVANESSIAN, A., Y MAURO, R., (Comps.), Ibid., p. 96.

${ }^{49}$ «La automatización, desde el punto de vista del capital, debe siempre, por lo tanto, ser compensada con nuevos modelos de controlar (o sea, de absorber y agotar) el tiempo y las energías así liberados. Debe producir pobreza y estrés donde debería existir riqueza y ocio. Debe hacer del trabajo directo la medida del valor aun cuando es evidente que la ciencia, la tecnología y la cooperación social constituyen la fuente de la riqueza producida.»I Ibid., p. 98.

${ }^{50}$ «La escenificación del encuentro entre "algoritmos" y "capital” como un problema político sugiere la posibilidad de romper con el hecho del "realismo capitalista" -la idea de que el capitalismo constituye la única economía posible- mientras, simultáneamente, afirma que las nuevas formas de organizar la producción y la distribución de la riqueza deben incorporar los desarrollos científicos y tecnológicos. El concepto del común, que va más allá de la oposición entre Estado y mercado, público y privado, es usado aquí como una forma de instigar el pensamiento y la práctica de un posible modo de existencia postcapitalista para los medios digitales en red». Ibid., pp. 92 y 93.

${ }^{51}$ Ibid., p. 103.

${ }^{52}$ Ibid., p. 106.

${ }^{53}$ Ibid., p. 107. 
hombre y máquina, para una mirada más o menos crítica resultaría evidente que esta propuesta supone más bien un fuga neocolonialista a máxima escala ${ }^{54}$ debido a la masiva evacuación de fuerza de trabajo humana ante la incorporación total de las tecnologías en el proceso productivo para mantener vivo, como último mecanismo de compensación, el verdadero origen de la innovación tecnológica: la competencia capitalista.

\section{El legado de Marx ante los interrogantes aceleracionistas: ¿encomienda o tropo?}

«Es Marx, junto con Land, el pensador paradigmático del aceleracionismo» ${ }^{55}$. Según los autores del MPA en tiempos de Marx, como en nuestros días, el capitalismo seguía siendo «el sistema económico más avanzado del momento. Sus beneficios no debían ser revertidos, sino acelerados más allá de las restricciones de la forma de valor capitalista» ${ }^{56}$. Se trataría entonces, para un aceleracionismo de izquierdas, de reorientar las mismas tecnologías capitalistas con vistas a fines comunes; mientras que, para el aceleracionismo de derechas, tematizado por Land, recordemos, se pretende acelerar el proceso para adelantar lo máximo posible el colapso interno de valorización.

Según los autores del MPA, existe en Marx una «tendencia aceleracionista reprimida ${ }^{57}$. Sin embargo, convierten, de manera oportunista, lo que podría ser una "tendencia" en la obra marxiana en una "constante" ". En consecuencia, centran su análisis de Marx únicamente en el Fragmento sobre las máquinas, sito en los Grundrisse, en el cual podría encontrarse in nuce la semilla a partir de la cual florecerá todo el planteamiento aceleracionista: si el capital fixe es

\footnotetext{
${ }^{54}$ Cfr. SINGLETON, B., "Maximum Jailbreak" en: AVANESSIAN A. Y REIS M. (COMPS.), Op. Cit., pp.135-152.

${ }^{55}$ WILLIAMS, A. Y SRNICEK N., Op. cit., p. 38.

${ }^{56}$ Ibid.

${ }^{57}$ Ibid., 40 .

58 «Es importante a este propósito la referencia al "Fragmento sobre las máquinas". En este texto, Marx afirma que el comunismo está contenido como posibilidad en los pliegues de la forma capitalista, como una tendencia implícita en el desarrollo tecnológico de la organización actual del trabajo y del conocimiento. Todo está ya en este texto: la potencia del general intellect, la constante intensificación de la productividad, la tendencia hacia la emancipación del tiempo de trabajo. La tendencia implícita en la organización tecnológica del capitalismo conduce a una nueva concatenación del conocimiento y las máquinas. Esta concepción inmanente del comunismo tiene algo que ver con la hipótesis aceleracionista, pero ocurre que un peligro teórico se evidencia: el riesgo de confundir esta potencialidad de desarrollo presente en la actual composición del trabajo y tecnología como una necesidad.» BIFO, F., Op. Cit., pp. 73 y 74 [Cursiva nuestra].
} 
necesario para el desarrollo del sistema capitalista, al encontrarse inscrito en el ADN de la productividad y en la huida hacia adelante del capital en la acumulación del valor, podría llegar un momento en que supondría la liberación de las fuerzas productivas y, por lo tanto, el trabajo sería superfluo. El gran cambio sustancial de los aceleracionistas con respecto a Marx consistiría en reemplazar la función de la maquinaria por la tecnología, lo cual transformaría cualitativamente el trabajo hacia una era postcapitalista, que habrá de ser, necesariamente, postindustrial. Sin embargo, a diferencia de Nick Land, no creen que este proceso sea automático — evitando así cualquier tipo de teleología—: precisamente en esto estriba el papel de la aceleración que, gracias a las plataformas digitales, funciona como estrategia política capaz de subvertir el capitalismo de manera radical y holística hacia formas democráticas de organización.

La producción maquínica es consecuencia directa de, entra en sinergia con y efectúa en grado máximo la exigencia del capital de reducir la necesidad de trabajo humano y de incrementar continuamente los niveles de producción. Sin duda la absorción del trabajador en el pujante organismo de la máquina reduce, más evidentemente que nunca, al trabajador a un utensilio del capital. Y con todo, Marx afirma de forma crucial y clara que estas dos formas de subsunción en el capital y en el sistema técnico de producción- no son, en principio, ni idénticas ni inseparables ${ }^{59}$

Vayamos a la fuente, el Fragmento sobre las máquinas, para poner a prueba la tesis que contiene la cita anterior, a saber: el desarrollo de las fuerzas productivas cristalizadas en la tecnología — gracias al avance de la ciencia y el conocimiento de las leyes de la naturaleza-no es ni idéntico ni separable del proceso de valorización del capital; aun cuando éste se empeñe en reducirlas a capital fijo, como medio de producción, para conseguir cada vez una mayor productividad.

Marx introduce la distinción, que empezaba a ponerse en juego en ese momento, entre el valor de uso de los medios de producción y su progresiva asunción como capital fijo tomado inmediatamente como valor de cambio a través de la maquinaria como sistema automatizado de producción: «el trabajador ya no introduce el objeto natural modificado, como eslabón intermedio, entre la cosa y sí mismo, sino que inserta el proceso natural al que transforma en industrial, como medio entre sí mismo y la naturaleza inorgánica, a la que domina. Se presenta al lado del proceso de producción [...] de modo que

${ }^{59}$ AVANESSIAN, A., Op. Cit., p. 14. 
los obreros mismos sólo están determinados como miembros conscientes de tal sistema» ${ }^{60}$.

A través de tal asunción, el trabajo vivo no se presenta inmediatamente como fuente de valorización, sino que, en apariencia, se convertiría en «mero accesorio vivo de esa maquinaria, en medio para la acción de ésta» ${ }^{61}$. Esta cuestión es la que retoman los aceleracionistas para desarrollar su estrategia política hacia el postcapitalismo: si la tecnología, que cristaliza el saber científico como potencia del desarrollo social, hace infinitamente pequeña la medida del valor - esto es, el trabajo socialmente necesario - al aumentar de manera exacerbada la productividad, sería posible utilizar políticamente esa misma herramienta, la tecnología, para dar con el «desarrollo libre de las individualidades, y por ende no reducción del tiempo de trabajo necesario con miras a poner plustrabajo, sino en general reducción del trabajo necesario de la sociedad a un mínimo, al cual corresponde entonces la formación artística, científica, etc., de los individuos gracias al tiempo que se ha vuelto libre y a los medios creados para todos [...] Esto redundará en beneficio del trabajo emancipado y es la condición de su emancipación» ${ }^{62}$.

Contrariamente a algunas variantes del marxismo que tienden a identificar completamente a la tecnología con el "trabajo muerto", el "capital fijo" o la "racionalidad instrumental" y, por tanto, con el control y los dispositivos de captura, parece importante recordar que, para Marx, la evolución de la maquinaria indica también un nivel de desarrollo de los poderes productivos que son liberados pero nunca completamente contenidos por la economía capitalista. Lo que interesaba a Marx (y lo que hace a su trabajo relevante todavía para aquellos que luchan por un modo de existencia postcapitalista) es

\footnotetext{
${ }^{60}$ MARX, K., Elementos fundamentales para la crítica de la economía política (borrador) $1857-$ 1858 Vol. II, Madrid, S.XXI, 1972, p. 218 y 228 [Cursiva nuestra].

No olvidemos que existe una raíz claramente hegeliana en la concepción del medio de producción como mediación entre la fuerza de trabajo y el producto de su trabajo que Hegel sintetiza en la expresión ardid de la herramienta en la Filosofia del Espíritu de Jena: «Pero la herramienta misma aún no conlleva la actividad; es cosa inerte, no vuelve en ella misma. Sigo teniendo que trabajar yo con ella; entre mí y la coseidad externa he interpuesto el ardid, para cuidarme y cubrir con él mi determinidad, dejando que se gaste la herramienta. Pero de este modo solo economizo cuantitativamente, pues al fin y al cabo también me salen callos, que hacen de mí una cosa; éste sigue siendo un momento necesario; la propia actividad del impulso aún no está en la cosa [...]. Aplicando cualquier actividad propia de la naturaleza -la elasticidad del resorte del reloj, el agua, el viento-, para que hagan en su existencia sensible algo completamente distinto de lo que quisieran hacer; su ciega acción se convierte en finalista, en lo contrario de ella misma: comportamiento racional de las leyes naturales en su existencia externa.» HEGEL, G. W. F., Filosofia real, Madrid, FCE, 2006, p. 169.

${ }^{61}$ MARX, K., Op. Cit., p. 219.

${ }^{62}$ Ibid., p. 224 y 229.
} 
la manera en que la tendencia del capital a invertir en tecnología para autonomizar y, por tanto, para reducir los costos del trabajo al mínimo, potencialmente libera un "excedente" de tiempo y energía (trabajo) o un exceso de capacidad productiva en relación con el trabajo fundamental, importante y necesario de reproducción (una economía global, por ejemplo, debería primero que nada producir suficiente riqueza para que todos los miembros de la población planetaria fuesen adecuadamente alimentados, vestidos, curados y alojados). Sin embargo, lo que caracteriza a la economía capitalista es que este excedente de tiempo y energía no es simplemente liberado, sino que es reabsorbido constantemente en el ciclo de producción de valor de cambio, lo que conduce a la creciente acumulación de riqueza por parte de unos pocos (el capitalista colectivo) a expensas de muchos (las multitudes) ${ }^{63}$

Como se puede ver en la cita anterior, para los aceleracionistas la liberación política tiene que ser realizada con las herramientas - tecnología y general intellect - forjadas por el capital y vueltas contra el capital mismo. Sin embargo, aunque resulta evidente que la tecnología lleva inscrito desde su surgimiento el estrechamiento de los fines marcados por la valorización del capital, los aceleracionistas, a través de su programa político, pretenden partir como hipótesis de un excedente de subjetividad, cuya potencia sea capaz de deshacerse de las formas de dominación subjetivas y objetivas, dejando asomar claramente un neoidealismo tras su posición postmaterialista. En esta línea, para los aceleracionistas la tecnología no implica necesariamente una relación alienante, sino que ésta estaría implicada únicamente en la forma capital, como si la alienación se circunscribiera solamente a la esfera del mercado - cuya centralidad, por otra parte, ha desaparecido de manera patente desde el hundimiento del capitalismo liberal - sin constituir la totalidad de las formas sociales. Sin embargo, hay que tener en cuenta que, según lo expuesto por Marx ${ }^{64}$ en el Fragmento, el capital sólo emplea la maquinaria en la medida en que permite al obrero relacionarse con una mayor parte de su tiempo como tiempo que no le pertenece: «sólo en la imaginación de los economistas acude [la maquinaria] en ayuda del obrero individual $»{ }^{65}$.

Siendo así, podría resultar llamativa la participación del célebre marxista Toni Negri, en el libro colectivo Aceleracionismo. Estrategias para una transición al postcapitalismo, en el cual reconoce el intento aceleracionista de actualizar algunas de las problemáticas que asaltaron a Marx trayéndolas a contexto contemporáneo, y valora como "urgentes, apropiados y realistas" los

${ }^{63}$ TERRANOVA, T., Op. Cit., pp. 97 y 98.

${ }^{64}$ Cfr. MARX, K., Op. Cit., p. 224.

${ }^{65}$ Ibid. 
tres objetivos contenidos en el MPA. En primer lugar, según Negri, Srnicek y Williams tratan de proporcionar una infraestructura filosófico-teórica como soporte para un nuevo proyecto político - de cuño idealista-. En segundo lugar, pretenden ganar para la causa el terreno de los medios de comunicación mainstream (Internet y las redes sociales). En tercer lugar, pretenden superar los límites del tipo de organización horizontalista, propios de la política folk, para construir nuevas y futuras formas institucionales postcapitalistas ${ }^{66}$.

No deja de ser curiosa la colaboración de Toni Negri en este volumen colectivo, pero cuando se estudian sus posturas, la simbiosis parece clara: mientras Negri ve transparentarse su concepto de multitud en las teorías aceleracionistas $^{67}$, éstos consiguen conectarse con el postoperaísmo italiano de los años 70, ganando así, además, capital cultural para situar sus teorías en el panorama intelectual actual.

¿Qué decir de ese documento? Algunos de nosotros lo sienten como un "complemento" postobrerista, nacido en terreno anglosajón, menos susceptible a reediciones del humanismo socialista, y más capaz de desarrollar un humanismo positivo. El nombre "aceleracionismo" es ciertamente infeliz, da un sentido "futurista" a algo que no lo es en lo más mínimo. El documento tiene indudablemente un sabor a actualidad, no solo en la crítica del socialismo y de la socialdemocracia "reales", sino también en el análisis y en la crítica de los movimientos de 2011 y siguientes. Plantea con fuerza extrema el tema de la necesidad de la tendencia del desarrollo capitalista, de la necesidad de su reapropiación y de su ruptura: en resumen, sobre esta base, propone la construcción de un programa comunista ${ }^{68}$

Negri aprecia el espíritu postobrerista de raíz anglosajona del MPA y ve en él una actitud crítica necesaria, y lo que es más importante: un intento de proponer una nueva hegemonía adaptada a la era de las TICs, que subestimaría, sin embargo, la dimensión cooperativa de la producción. Para Negri todo el discurso del MPA se basa en la capacidad para liberar las fuerzas productivas del trabajo cognitivo, es decir, en una reactualización del principio fundamental del materialismo revolucionario: liberar las fuerzas productivas latentes, en este caso, las fuerzas productivas del trabajo cognitivo ${ }^{69}$. De esta manera, parece que

\footnotetext{
${ }^{66}$ Cfr. NEGRI, A., Op. cit., p. 83.

${ }^{67}$ «Entiendo este pasaje de la siguiente manera: es necesario madurar la totalidad del complejo de las posibilidades productivas del trabajo cognitivo para proponer una nueva hegemonía.» NEGRI, A.., Ibid., p. 82. [Cursiva nuestra].

${ }^{68}$ NEGRI, A.., Ibid., p. 84.

${ }^{69}$ Cfr. NEGRI, A.., Ibid., p. 80.
} 
Negri reconoce el potencial transformativo del aceleracionismo precisamente en la medida en que se solapa con su propio desarrollo teórico.

Lo que para Negri resulta fundamental es qué hay de $\operatorname{común}^{70}$ en la tecnología como relación social, sin embargo, lo que interesa a los aceleracionistas es cuánto se puede construir de común a partir de la tecnología. Por ello, Negri critica al MPA en tanto que éste no podría dejar de ser un mero manifiesto, no pudiendo llegar nunca a convertirse en un programa político real, pues si algo hemos aprendido del S.XIX es que, aun cuando se tengan los medios para la revolución, lo que siempre ha faltado ha sido un sujeto, un agente para el cambio social. Autoabanderarse como clase social elegida, en términos de (neo)proletariado, ya nunca más fue posible tras la caída del fordismo. Sin embargo, este intento parece reactualizarse por parte de los aceleracionistas al referirse a sí mismos como cognitariado debido al auge de las TICs y el trabajo inmaterial. No deja de resonar en ello el eco de la manida concepción de la ideología como velo, siendo así que el cognitariado sería la nueva clase social revolucionaria que identificaría los viejos significantes "base" y "superestructura" con las tecnologías y factores económico-financieros respectivamente, invirtiendo con ello la clásica relación debido a su enfoque postmaterialista. Por ello, los aceleracionistas cifran todo el potencial revolucionario en lo mudable (las modas, los hypes, etc.) del capitalismo, mientras que desatienden precisamente aquello que le es inmutable: las crisis cíclicas dentro del proceso de valorización, los factores histórico-materiales, etc. coherentemente con su posición postmaterialista. Sin embargo, tras ello se deja deslizar el intento de tildar como "verdadera" contradicción capitalista solamente la lucha de clases y no la contradicción entre capital-trabajo.

¿Cuál sería el desliz común que comparten, sintomáticamente, tanto Negri como los aceleracionistas respecto de la comprensión de la teoría del valor marxiana? Confundir el concepto de trabajo abstracto con el de trabajo inmaterial. De esta manera, el punto ciego de su crítica es precisamente la piedra angular del capitalismo: «la transformación del trabajo en valor, [...] al contrario, es considerada como un hecho ontológico, neutro e incluso positivo» ${ }^{71}$. No poniendo esto en cuestión se centran, simplemente, en el análisis de los cambios

\footnotetext{
${ }^{70}$ «Llamo la atención sobre este punto: cuando se plantea este problema, se plantea implícitamente (aceptando la progresividad de la tendencia productiva) el problema de definir mejor el proceso en el cual se forma y se consolida la relación entre la singularidad y lo común. Debemos especificar cuánto de común hay en cada ensamblaje tecnológico, desarrollando una profundización específica de la antropología productiva.» NEGRI, A., Ibid., p. 86.

${ }^{71}$ JAPPE, A., Las aventuras de la mercancía, Logroño, Pepitas de calabaza, 2016, p. 225. Para las siguientes líneas, nos hacemos cargo de la crítica que realiza Anselm Jappe a Negri, la cual pensamos que puede ampliarse al enfoque aceleracionista.
} 
suscitados en la dimensión social, es decir, en la mera superficie sociológica de las nuevas formas de organización del trabajo vivo que han traído consigo las innovaciones tecnológicas y cuáles son los efectos suscitados como correlato subjetivo $^{72}$ a la hora de conformar un nuevo agente revolucionario. Esto no les permitiría distinguir entre trabajo productivo, trabajo reproductivo y trabajo improductivo ${ }^{73}$.

Ciertamente, como hemos señalado anteriormente, después de la revolución microelectrónica resulta extremadamente complicado determinar el input de tiempo inmediato empleado de trabajo vivo. Sin embargo, esto no indicaría la posibilidad fáctica de liberación de la forma valor, sino más bien su contrario: al no poder distinguir ya entre tiempo productivo y tiempo libre debido a la conquista total de la vida cotidiana por parte del capital, se evidencia el absoluto aprisionamiento de las relaciones productivas por la forma valor. Es más, ante la progresiva evacuación de fuerza de trabajo humana — recordemos, según Marx, la única fuente de valorización por la sencilla razón de que el capital es una relación social - debido al brutal aumento de productividad mediante la introducción de tecnología se pone de manifiesto el progresivo colapso en lo que de reproducción social tiene el capital: cada vez más población resulta superflua para el sistema, convirtiéndose así, sin grandes resistencias políticas, el mediterráneo en una fosa común.

Sin embargo, tanto Negri como los aceleracionistas ven en el trabajo inmaterial una oportunidad para articular, más o menos espontáneamente, un nuevo agente revolucionario que, si bien puede ser llamado multitud, o cualquier otro sintagma más o menos pomposo, tras él no deja de resonar el viejo concepto de proletariado. Efectivamente, esta posición no resulta ser más que «la última mascarada del marxismo tradicional» ${ }^{74}$, puesto que, dictaminando como obsoleta la teoría del valor marxiana debido al auge tecnológico en el proceso productivo, se centran en señalar como contradicción fundamental la lucha de clases dejando intacto el propio proceso de valorización.

El ordenador sería pues el instrumento que hace realidad el viejo sueño de los marxistas tradicionales de un trabajo que crea valor sin intervención del capital. [...] Imperio se dirige a un público muy preciso en términos sociológicos: sugiere a las nuevas capas medias que se ganan el pan en el sector "creativo"-

\footnotetext{
72 «Si el pensamiento sobre la vigilancia es ante todo anglosajón, puede decirse que el de las "subjetividades controladas" es básicamente italiano: Paolo Virno, Antonio Negri, Maurizio Lazzarato.» RODRÍGUEZ, P. E., ¿Qué son las sociedades de control?, Sociedad, Buenos Aires, UBA-CONICET, ISSN: 0327-7712, p. 5.

${ }^{73}$ Cfr. JAPPE, A., Op. Cit., pp. 223-228.

${ }^{74}$ Ibid., p. 223.
} 
informática, publicidad, industria cultural- que ellas representan el nuevo sujeto de transformación de la sociedad. El comunismo será hecho realidad por un ejército de microemprendedores de la informática ${ }^{75}$

En resumen, los aceleracionistas en su análisis preservan de Marx aquello que la transformación histórica ha dejado atrás: la concepción epocal que valora como positivo el progreso que implica la modernización y autonomización del proceso productivo como ventana de oportunidad hacia la emancipación total. Esto denota cierta confianza, todavía hoy, en el rumbo que ha tomado la civilización en los dos últimos siglos, aun cuando el curso de la historia se ha empeñado, a partes iguales, en identificar civilización y barbarie ${ }^{76}$.

Sin embargo, una de las herramientas más valiosas que nos dejó Marx para seguir desgranando nuestro presente, la teoría del valor en sí misma, es desechada por su apariencia fenoménica en la actualidad como "trabajo inmaterial". Es más, si para Marx no deja de ser central el concepto de trabajo para su análisis de la sociedad capitalista, no es porque crea fundamental la producción material para el sostenimiento de la vida social ni, por otro lardo, que sea el trabajo el locus de la realización de la libertad social - ya que esto no dejaría de reiterar la robinsonada ricardiano-hegeliana-; sino que Marx ha sido capaz de considerar el trabajo en su especificidad abstracta y el carácter dinámico, inmanente y contradictorio de la sociedad capitalista como una característica históricamente determinada del capitalismo como relación social ${ }^{77}$. De hecho, precisamente, como la síntesis social característica del capitalismo es inmanentemente contradictoria, éste presenta las áreas de actividad productiva como fragmentadas y no necesariamente mediadas entre sí. Probablemente esta apariencia de "contingencia" entre los medios de producción y las fuerzas productivas sea la que induzca a pensar a los aceleracionistas que «los desarrollos científicos y teóricos se consideren funciones inmanentes del

\footnotetext{
${ }^{75}$ Ibid., pp. 225 y 227.

${ }^{76}$ «El botín es arrastrado en medio del desfile del triunfo. Y lo llaman bienes culturales. Éstos han de contar en el materialista histórico con un observador ya distanciado. Pues lo que de bienes culturales puede abarcar con la mirada es para él [...] de una procedencia en la que no puede pensar sin horror. Su existencia la deben no ya sólo al esfuerzo de los grandes genios que los han creado, sino también, sin duda, a la servidumbre anónima de sus contemporáneos. No hay documento de cultura que no lo sea, al tiempo, de barbarie.» BENJAMIN, W., "Sobre el concepto de historia" en: Obras I/2, Madrid, Abada, 2008, p. 309.

${ }^{77}$ Cfr. POSTONE, M., Tiempo, trabajo y dominación social. Una reinterpretación de la teoría crítica de Marx, Barcelona, Marcial Pons, 2006, pp. 162 y 163.
} 
pensamiento o de disciplinas independientes, y no se entiendan en referencia a procesos sociales reales» ${ }^{78}$.

La hipótesis aceleracionista se funda en dos puntos centrales: el primero es la asunción de que acelerar los ciclos de producción hace al capitalismo inestable; el segundo es la afirmación de que las potencialidades contenidas en las formas capitalistas están destinadas a desplegarse necesariamente ${ }^{79}$

No deja de ser sintomático que Williams y Srnicek, los mismos autores del MPA, unos años más tarde, en Inventar el futuro. Poscapitalismo y un mundo sin trabajo prescindan del término aceleracionismo ${ }^{80}$ y no vuelvan a nombrar a Deleuze y Guattari ${ }^{81}$. Esto, aunque no deja de ser llamativo, puede tener su explicación en que, si uno lee atentamente, el aceleracionismo de izquierdas realmente no parece pretender acelerar como tal el proceso capitalista de valorización, sino reabsorber el general intellect como cristalización de la totalidad de las fuerzas productivas para el cambio político. De esta manera las potencialidades de la tecnología contenidas en el germen capitalista no están destinadas a desplegarse necesariamente (casi teleológicamente), como afirma Bifo en la cita anterior, sino que necesitan de intervención política, que es precisamente en lo que estriba el aceleracionismo como estrategia política. Esto

\footnotetext{
${ }^{78}$ POSTONE, M., Ibid., p. 164. Quisiéramos advertir que esta tesis, tal y como nos recuerda Postone, ya fue desarrollada por Max Horkheimer en el famoso texto Teoría tradicional y teoría crítica de 1937.

${ }^{79}$ BIFO, F., Op. Cit., p. 74.

80 «In 2013, Nick Srnicek and Alex Williams sought to resolve this intolerable -even 'schizophrenic'- ambivalence in their 'Manifesto for an Accelerationist Politics,' which aimed to precipitate a specifically anti-capitalist 'Left-accelerationism', clearly demarcated over against its abominably pro-capitalist 'Right-accelerationist' shadow. This project - predictably- was more successful at re-animating the accelerationist question than at ideologically purifying it in any sustainable way. It was only by introducing a wholly artificial distinction between capitalism and modernistic technological acceleration that their boundary lines could be drawn at all. The implicit call was for a new Leninism without the NEP (and with the Utopian techno-managerial experiments of Chilean communism drawn upon for illustration). [...] At the time of writing, Left-accelerationism appears to have deconstructed itself back into traditional socialist politics, and the accelerationist torch has passed to a new generation of brilliant young thinkers advancing an 'Unconditional Accelerationism'». LAND, N., Op. Cit. https://jacobitemag.com/2017/05/25/a-quick-and-dirtyintroduction-to-accelerationism/ Consultado: 15 de septiembre 2019.

${ }^{81}$ Ya que Deleuze y Guattari parecen ser conscientes de los límites históricos que determinan los "agenciamientos colectivos" en la reapropiación del capital fijo y en la transformación de la fuerza de trabajo, los lenguajes, las antropologías y las actividades, y que tendrían que ver, tanto con la determinación de un umbral histórico, como con la toma de conciencia de una modalidad específica de la relación entre composición técnica y la composición política del proletariado. Cfr. NEGRI, A., Op. Cit., pp. 85 y 86.
} 
les acercaría a una postura, digamos, bastante tradicional dentro del marxismo y desde luego, nada novedosa.

\section{Con $y$ contra Marx. Conclusiones: síntomas, diagnósticos y pronósticos.}

Como hemos señalado al término del apartado anterior, hay que reconocer que en Marx aparece un diagnóstico de la sociedad capitalista como la más desarrollada hasta ese momento histórico, lo cual es síntoma del espíritu epocal de confianza en el "progreso" que implica el proceso de modernización ${ }^{82}$; mientras que los aceleracionistas dan un paso más allá al convertir ese síntoma epocal del S. XIX, es decir, la confianza en el avance del camino seguro de la ciencia y su aplicación tecnológica como esfera neutral, en la herramienta para producir políticamente un pronóstico social de emancipación total.

En esta engañosa situación social no solo no habría que olvidar a Marx, sino que habría descubrirlo por fin y leer su teoría con nuevos ojos, como una teoría del desarrollo y de las crisis del sistema moderno de producción de mercancías (un concepto que, desde un punto de vista lógico, abarca tanto al capitalismo occidental como a los sistemas de modernización rezagada de los socialismos de estado). Semejante lectura de la teoría de Marx, "a contrapelo" de su interpretación habitual, exige sin duda dos cosas. En primer lugar, su historización: es decir, quitarle el polvo a aquellos elementos en los que el propio Marx pensaba aún dentro del horizonte de modernización burguesa. Pero, en segundo lugar, esa lectura requiere dar un giro de ciento ochenta grados a la teoría de Marx; esto es, no entenderla ya como una representación

\footnotetext{
${ }^{82}$ «La subjetividad burguesa interpreta esta conexión como algo positivo y ya interiorizado. Y en la medida en que Marx argumenta desde una perspectiva de teoría de la modernización, también encontramos en él esta positivización. En este sentido la obra de Marx se revela como descendiente de la ideología liberal y de la doctrina económica clásica; aunque dé muerte a la teoría-madre, su obra sigue llevando los rasgos maternos. Pero precisamente este Marx positivista es el conocido Marx "exóterico" del movimiento obrero y lucha de clases» KURZ, R., Marx 2000. La importancia de una teoría dada por muerta para el Siglo XXI, Constelaciones. Revista de teoría crítica, $\mathrm{n}^{\circ} 8 / 9$ (2016-2017) ISSN: 2172-9506, p. 31. Puntualizamos aquí la diferencia entre dos rasgos vislumbrados por Kurz en la obra marxiana: por un lado, como comenta en la cita anterior, se encontraría el Marx "exóterico", el cual cristalizaría la contradicción entre capital-trabajo meramente en la lucha de clases como síntoma de su época — uno de los textos que pertenecerían a esta veta marxiana sería claramente el Manifiesto comunista-; por otro lado, se encontraría el Marx "esotérico", el cual trasciende su propia época caracterizando el sistema productor de mercancías a través de la crítica del fetichismo, del trabajo abstracto y de la forma valor.
} 
positivista de las categorías capitalistas (que a continuación habría que dominar en la forma no revocada de subjetividad burguesa), sino - al contrario- como su crítica inmanente radical. En otras palabras, habría que reconocer en la teoría de Marx las contradicciones históricamente condicionadas y superarlas. Sólo con un signo negativo en vez de uno positivo puede convertirse esta teoría de nuevo en una carga teórica explosiva ${ }^{83}$

Por ello, no deja de ser curioso que el último párrafo del Discurso sobre el libre intercambio de $1848^{84}$ sea evocado tanto en el artículo A Quick and Dirty Introduction to Accelerationism de Nick Land, como al comienzo del libro colectivo coordinado por los aceleracionistas de izquierdas. Esta recurrencia denota la íntima relación con el uso del término "aceleración" acuñado por éstos: lo que para Marx es claramente un sarcasmo sobre la capacidad corrosiva del capital para el mantenimiento de las relaciones sociales

"celebrando" la disolución de las férreas estructuras feudales-, para los aceleracionistas esa misma capacidad destructiva del tejido social se convierte en el súmmum de la liberación social, ya que permitiría construir un futuro absolutamente nuevo.

Y es que si bien es cierto que Marx, en el Fragmento sobre las máquinas, se resiste a reducir la potencialidad del general intellect a la mera finalidad de la valorización del capital; esto no significaría en ningún caso, frente a la postura aceleracionista, que continuando con el diagnóstico del filósofo renano, se pudiera llegar a inducir que precisamente la tecnología fuese la llave maestra suficiente para liberar las relaciones sociales vehiculadas por las ataduras del capital. La tecnología, al fin y al cabo, resulta ser tanto la cristalización de las fuerzas productivas como el medio necesario de producción. Por ello, no puede llegar jamás a eliminar totalmente de la ecuación el tiempo inmediato de trabajo - aun cuando el capital fixe reduzca al mínimo socialmente necesario la unidad de tiempo empleada - puesto que la fuerza de trabajo humana es y siempre será la única fuente de valorización.

[La maquinaria] no entra en escena para sustituir fuerza de trabajo faltante, sino para reducir a su medida necesaria la que ya existe masivamente. [...] El capital mismo es la contradicción en proceso, [por el hecho de] que tiende a reducir a

\footnotetext{
${ }^{83}$ KURZ, R., Ibid., p. 30 [Cursiva nuestra].

${ }^{84}$ «Pero en general, en nuestros días, el sistema protector es conservador, mientras que el sistema del libre intercambio es destructor. Disuelve las antiguas nacionalidades y lleva al extremo el antagonismo entre la burguesía y el proletariado. En una palabra, el sistema de la libertad comercial acelera la revolución social. Sólo en este sentido revolucionario, señores, voto en favor del libre intercambio». MARX, K., Miseria de la filosofia, México, S. XXI, 1987, p. 158.
} 
un mínimo el tiempo de trabajo, mientras que por otra parte pone al tiempo de trabajo como única medida y fuente de la riqueza. Disminuye, pues, el tiempo de trabajo en la forma del trabajo excedente; pone por tanto, en medida creciente, el trabajo excedente como condición - question de vie et de mortdel necesario. Por un lado despierta a la vida todos los poderes de la ciencia y de la naturaleza, así como de la cooperación y del intercambio sociales, para hacer que la creación de la riqueza sea (relativamente) independiente del tiempo de trabajo empleado en ella. Por el otro lado se propone medir con el tiempo de trabajo esas gigantescas fuerzas sociales creadas de esta suerte y reducirlas a los límites requeridos para que el valor ya creado se conserve como valor ${ }^{85}$

La maquinaria, entendida como sistema automático y capital fijo que aumenta la productividad reduciendo al mínimo el tiempo socialmente necesario, no conllevaría necesariamente la liberación de las relaciones sociales de la dictadura del tiempo del capital; más bien, ésta funciona al resguardo de una reserva de trabajo excedente a la espera de ser incorporado en la socialización capitalista que, expulsa y, al mismo tiempo, necesita — question de vie et de mort-para sobrevivir como sistema de reproducción social total. Esto apunta implícitamente a la conocida "ley de la caída tendencial de la tasa de beneficio" 86 , a la cual se aferran las teorías de la utilidad marginal y las doctrinas subjetivistas del valor con el fin de disolver «el concepto de valor en la manifestación del precio y [derivar] a su vez el precio del cálculo de utilidad puramente subjetivo de los participantes en el mercado» ${ }^{87}$.

La tasa de beneficio es la relación de la ganancia empresarial respecto al conjunto de costes previos en el proceso productivo. De esta manera, al final de un proceso de reproducción de capital, se necesita recuperar dichos costes previos y, además, generar un excedente. Al introducir capital fijo, éste "traslada" siempre la misma cantidad de valor en el proceso productivo desgastándose como material muerto. Por lo que, aun cuando aumenta la productividad, la cantidad de valor por cada mercancía es menor, teniendo así que compensar dicho mecanismo sobreproduciendo masivamente mercancías o abaratando el capital constante para poder recuperar los costes previos, tal y como ocurrió en el fordismo. Sin embargo, ese "excedente" necesario para la tasa de beneficio sólo puede provenir de la fuerza de trabajo humana, ya que es la que produce valor adicional al mero capital fijo. Pero, como hemos comentado

\footnotetext{
${ }^{85}$ MARX, K., Op. cit., p. 225 y 229 [Cursiva nuestra].

${ }^{86}$ En lo referente a la crítica del uso de las teorías de utilidad marginal de la ley de la caída tendencial de beneficio seguimos a: Cfr. KURZ, R., Op. Cit., pp. 36-41.

${ }^{87}$ KURZ, R., Ibid.., p. 34.
} 
antes, al introducir maquinaria en el proceso productivo, irremediablemente se reduce relativamente la fuerza de trabajo, por lo que la ganancia también tenderá a reducirse en relación con el capital empleado.

No obstante, contra las teorías marginalistas y el enfoque que trasluce el aceleracionismo, esto no supondría meramente una caída de la tasa relativa del beneficio - la cual indicaría, según ellos, el límite de la producción capitalista; sino que, guiándonos de nuevo por el diagnóstico de Kurz, esto supondría, más bien, una caída absoluta de la masa de valor ${ }^{88}$, ya que se ha hecho imposible continuar con la expansión de los mecanismos de compensación, agotando éste último recurso, en 2008, como simulación del valor en el futuro a través del crédito.

Por tanto, ese "tiempo libre" que generaría la alta productividad gracias a la incorporación masiva de tecnología como capital fijo en el proceso de producción sería, en nuestros días - cuando este proceso ha entrado en paroxismo $^{89}$ - , un mero eufemismo del desempleo estructural masivo: el tiempo

\footnotetext{
${ }^{88}$ Un ejemplo visual paradigmático de este proceso lo encontramos en el filme británico The man in the white suit (1951), dirigido por Alexander MacKendrick. Allí nos encontramos con un científico, el cual trabaja en las fábricas textiles de Inglaterra, que da con un tejido incorruptible, no pudiéndose romper ni manchar de ninguna de las maneras. En ese momento, tanto el movimiento obrero como la patronal intentan desesperadamente impedir al científico seguir adelante con la patente, ya que ésta pondría el fin a la continuación de los procesos productivos textiles. Esto pone de relieve varios asuntos expuestos en este artículo: en primer lugar, el valor de uso sólo resulta un mal necesario para la valorización del capital, por lo que, en segundo lugar, la supuesta independencia de la ciencia respecto de dicho proceso es simple apariencia de la fragmentación social que el capital necesita para su reproducción, y en tercer lugar, se observa claramente cómo tanto el movimiento obrero como los capitalistas son meros "suboficiales" del capital, uniéndose, paradójicamente, ambos agentes sociales en torno a la burbuja del trabajo abstracto.

${ }^{89}$ Para consultar la tesis sobre el límite interno de valorización que Robert Kurz — exponente de la Wertkritik, corriente antiacadémica que se propone reactualizar en los años ochenta la teoría del valor marxiana, y en quien nos apoyamos específicamente para este punto- desarrolla a lo largo de toda su obra como resultado del proceso de modernización - en concreto después de la revolución microelectrónica - y con él, la caída del patrón oro, el surgimiento del capital financiero y el desmantelamiento de los Estados de bienestar:

Cfr. KURZ, R., Die Substanz des Kapitals. Abstrakte Arbeit als gesellschaftliche Realmetaphysik und die absolute innere Schranke der Verwertung, EXIT! Krise und Kritik der Warengesellschaft, $\mathrm{n}^{\circ} 1$, Bad Honnef, Horlemann, 2004, pp.44-129, KURZ, R., El colapso de la modernización. Del derrumbe del socialismo de cuartel a la crisis de la economía mundial, Buenos Aires, Marat, 2016 y KURZ, R., Marx 2000. La importancia de una teoría dada por muerta para el Siglo XXI, Constelaciones. Revista de teoría crítica, nº8/9 (2016-2017) ISSN: 2172-9506, pp. 28-45.
} 
libre de Los lunes al sol ${ }^{90}$, un tiempo que produce marginación, exclusión social y efectos subjetivos patologizados.

En este sentido, para poder siquiera pensar en deshacernos del capitalismo como sistema de reproducción social total, esto es, como organismo social, habría que desarticular su átomo más esencial: el trabajo abstracto como categoría fetichista, esto es, «la reducción efectiva de toda actividad a un simple gasto de energía, [ya que] esta reducción es "efectiva" en el sentido de que las actividades particulares - y de igual manera, los individuos que las realizansólo se vuelven sociales en cuanto quedan reducidas a dicha abstracción» ${ }^{91}$.

Para luchar contra el capitalismo y sus formas de dominación social, parece que el único camino que nos queda en la actualidad es desarticular la raíz misma del proceso de valorización: el trabajo abstracto. Tarea que, efectivamente, nunca abandonó Marx a lo largo de toda su vida, ya que «si nos atenemos al auténtico contenido de la obra de Marx, no representa una teoría positiva de la "construcción del socialismo", sino muy al contrario una teoría negativa de la crisis del sistema productor de mercancías»"

\section{Bibliografía}

AVANESSIAN, A., Y MAURO, R., (Coomps.), Aceleracionismo. Estrategias para una transición hacia el postcapitalismo, Buenos aires, Caja negra, 2017. BENJAMIN, W., "Sobre el concepto de historia" en: Obras I/2, Madrid, Abada, 2008, p. 309.

DELEUZE, G., y GUATTARI, F., El Anti-Edipo, Barcelona, Paidós, 1985. HEGEL, G. W. F., Filosofía real, Madrid, FCE, 2006.

JAPPE, A., Las aventuras de la mercancía, Logroño, Pepitas de calabaza, 2016. KURZ, R.,El colapso de la modernización. Del derrumbe del socialismo de cuartel a la crisis de la economía mundial, Buenos aires, Marat, 2016.

\footnotetext{
${ }^{90}$ Conocida película española del 2002 que ganó el premio Goya, dirigida por Fernando León de Aranoa, ambientada en los años ochenta durante la reconversión industrial de la ciudad de Vigo (Galicia, España) en la que se refleja la exclusión social causada por la falta de trabajo gracias al auge del proceso de modernización, resultando otro buen ejemplo visual para este punto.

${ }^{91}$ JAPPE, A., "De lo que es el fetichismo de la mercancía y sobre si podemos librarnos de él" en: MARX, K., El fetichismo de la mercancía (y su secreto), Logroño, Pepitas de calabaza, 2014, p. 15 [Cursiva nuestra].

${ }_{92}$ KURZ, R., Op. Cit., (2016-2017), p. 29.
} 
Marx 2000. La importancia de una teoría dada por muerta para el Siglo XXI, Constelaciones. Revista de teoría crítica, $\mathrm{n}^{\circ} 8 / 9$ (2016-2017) ISSN: 21729506, pp. 28-45.

Die Substanz des Kapitals. Abstrakte Arbeit als gesellschaftliche Realmetaphysik und die absolute innere Schranke der Verwertung, EXIT! Krise und Kritik der Warengesellschaft, $\mathrm{n}^{\mathrm{o}} 1$, Bad Honnef, Horlemann, 2004, pp.44129.

MARX, K., Elementos fundamentales para la crítica de la economía política (borrador) 1857-1958, Madrid, S. XXI, 1972.

El fetichismo de la mercancía (y su secreto), Logroño, Pepitas de calabaza, 2014. Miseria de la filosofía, México, S. XXI, 1987.

POSTONE, M., Tiempo, trabajo y dominación social. Una reinterpretación de la teoría crítica de Marx, Barcelona, Marcial Pons, 2006.

SRNICEK, N., Y WILLIAMS, A., Inventar el futuro. Poscapitalismo y un mundo sin trabajo, Barcelona: Malpaso, 2017.

RENDUELES, C., "Tecnociencia y posthumanismos: del general intellect al ciberfetichismo" en: ACOSTA, L., y LÓPEZ, P., (Eds.), La técnica moderna y las "superaciones del hombre", Guillermo Escolar Editor, 2019, pp. 187-203.

RODRÍGUEZ, P. E., ¿Qué son las sociedades de control?, Sociedad, Buenos Aires, UBA-CONICET, ISSN: 0327-7712.

VV.AA., \#Acelerate\# The acelerationist reader, United Kingdom, Merve Verlag, 2014.

Fuentes electrónicas

BYUNG-CHUL, H., ¿Por qué hoy no es posible la revolución?, El país, 3 de octubre de 2014: https://elpais.com/elpais/2014/09/22/opinion/1411396771_691913.html. Consultado: 13 septiembre 2019.

CYBERSYN. Sinergia Cibernética: http://www.cybersyn.cl/castellano/cybersyn/index.html Consultado: 15 de septiembre 2019.

LAND, N., A quick and dirty introduction to accelerationism, Jacobite, 25 de mayo de 2017, https://jacobitemag.com/2017/05/25/a-quick-and-dirtyintroduction-to-accelerationism/ Consultado: 15 de septiembre de 2019. 


\section{SECCIÓN BIBLIOGRÁFICA / REVIEWS}


